\title{
Deconstructing the Web -a curriculum for media students
}

\author{
Clint Cockcroft \\ Department of Journalism and Media Studies, Rhodes University, South Africa
}

\section{Contents}

1. Introduction

2. A time of change

3. Division of labour

4. Curriculum

5. National qualifications framework

6. Appendix 1

7. Appendix 2

8. Appendix 3

9. Appendix 4

\section{Introduction}

There is an ongoing dialogue aimed at determining the needs of senior Journalism students who have chosen to specialize in new media. The Internet industry is currently staffed by people from a variety of backgrounds applying their skills from other areas within this new arena. The Rhodes New Media Lab, a unit within the Department of Journalism and Media Studies, is paralleling the maturing of the on-line sector by offering a course aimed specifically at training students in this emerging field.

Currently we are in a time of transition between two significantly distinct offerings aimed at preparing different students for vastly differing roles in the market place. Currently we teach two option courses: the Metropolis New Media Programme, which focuses on on-line publishing, and Computer Aided Research and Reporting. This article primarily concerns itself with the former, although in certain respects the two are intimately linked. They are connected more substantially in the second of the courses offered by the laboratory, the New Media Specialization. This commences in 2001 and combines material from both options while developing them further, in addition to encompassing new areas.

Students are required to accrue ten credits during their fourth post-graduate year: the specialization is worth six while the option is an elective worth two. The time allotted leaps from 65 to 480 hours, making for dramatically different courses. However, the most informative distinction between the course and more directly the current discussion, is the intended occupation for which students are preparing. The option provides students training 
in other areas with new media skills, while the specialization needs to cater for all the outcomes of the intended job description.

With the industry in a continuous state of transition and redefinition, as well as maturing from a tool of the scientific community to an almost mainstream social and economic phenomenon, the current situation provides few cues and pegs on which to construct a course. Employers are not providing a coherent job description, but are in general terms articulating staffing needs and the direction in which the plan needs to develop in relation to industry trends. Our brief for the curriculum development process and writing of outcomes involves the marrying of a great many factors, most of which are not quantifiable or explicit.

\section{A time of change}

There is a significant 'hole' in the system of authority and hierarchy in most current new media-related environments. The perception and hype that the Internet is something dramatically new are allowing graduates opportunities traditionally reserved for experienced management and offering them freedom far beyond their 'old media' peers. This however, has implications for students' formal educational needs, as they will need to be orientated towards many more of the structures within an organization.

Although the nature of the new media industry may lead to a more varied and fluid set of employment and development criteria for some time, a degree of formalization is occurring. This year has seen a considerable maturation of the Internet both in terms of technology and industry organization.

\section{Technology}

- The trend has been away from static html to dynamic pages, both on the client-side and in terms of delivery

- Heavy utilization of database technology: personalization and user interaction

- Multiple media utilization: video, audio and animation

- Bandwidth, browser development and infrastructure developments

- Embryonic stages of alternative delivery devices

- Complexity and sophistication of the programming has exploded and will continue unabated.

Even this cursory snapshot reveals a situation of increasing complexity within the production process, as well as the range and level of skills being demanded. While it is reasonable to expect a degree of 'multi-skilling', there is a strong argument suggesting an increased emphasis on production management, team dynamics and an understanding of the dynamics of how various media interact.

\section{Industry}

- Mergers and acquisition creating a 'traditional' corporate scenario

- The idea of a 'new economy' coming under scrutiny with some commentators dismissing it as hype

- Internet strategies falling into existing management, financing, marketing, etc. structures

- Stocks being re-evaluated and start-ups needing to have comprehensive business plans

- Investors demanding on-line companies to show a profit in the relatively near future. 
Again even a brief tour of recent developments exposes an era of rapid change, with uncertainty and new demands a daily reality. In many ways the on-line presence is a virtual representation and gateway of the real world organization, which needs to perform tasks required by both while strategically integrating vastly differing realities at play. The direct consequence of this is that the 'new media specialist' is required to act as a translator to all parties with an on-line stake. This requires an in-depth understanding of all aspects of the medium and an orientation to the roles involved in the full production process: from conception of strategy to construction, marketing, sales, administration, communication, financing, management and analysis.

Consideration of the university environment will reveal further elements in developing a curriculum, as will factoring in the media filter provided by our context. These direct us far more easily towards a 'new media manager' or 'multiple media content creator' than any manner of operator whether it be coder, graphic designer, writer or any other media producer.

The continual intensification of professionalism and complexity gripping the medium, with e-commerce taking up the central position, has led to the dating of previous on-line staff models. Until recently, the dominant scenario was that of one person or small team being 'all things' to a site, with little responsibility and awareness outside that framework. The most striking flaws were a lack of integration with the strategies and structures of the organization as well as overall weakness, be it with site structure, graphic design, programming or needs analysis.

\section{Division of labour}

Taking an overview of the entire production process within a university context, the exercise of placing areas of responsibility with academic departments provides further clarity as to our specific role. Referring to the table in Appendix 1 it is possible to focus our activity to some degree. As a journalism and media studies department our business is content production but, as the table reveals, there are several components involved.

Clearly in most media it is safe to assume that a department of this nature is aimed at producing content creators. It is equally safe to argue that the course under question is focused on producing on-line content creators with skills honed to the specifics of on-line publishing. The task involved here is the production of Web-specific material or the translation of existing content into a more appropriate format.

Even the terms used to describe the role of the content producer and/or manager are fluid and rendered meaningless by their lack of conventional acceptance. 'Web designer' could be used as a container phrase or to refer to a number of specific yet varied roles within the overall scheme. The word 'webmaster' could refer to the manager of an entire complex production project, the coder or designer, or even just the person that replies to e-mail. 'Journalist', 'content creator', 'site-master' or 'manager', etc. are all lacking, misleading or inaccurate terms in some way, at least in terms of the role we are training our student towards. Within the new media laboratory we most commonly use the terms 'new media specialist' or less often 'online content producers'. While these are more accurate they are of no real use without widespread understanding of what is being referred to.

Whatever the function of a site, the task of content production falls on communication specialists, leading to a core role in strategy and project management. The latter is where the university course reveals its strength, with the crucial areas of analysis and planning drawn 
out of a theoretical foundation. The table in Appendix 2 portrays an image of unjustified clarity, whereas in reality the entire process is prone to enormous expansion and contraction and is notorious for loosely defined job descriptions and tasks. As the process and the industry become more sophisticated and professional roles begin by necessity to become specialized, creating a scenario similar to the one outlined will become more of a reality.

It could be argued that a site is a virtual organization necessitating a site creator and maintainer orientated to many different areas of study. Even with significant input from experts or users in such areas as sales, marketing and management, the designer of the system still needs to create a clear, logical and easily usable interface. Product and site marketing offer the additional dimensions of attracting and holding the potential customer's attention, while promoting the image or 'feel' that is going to encourage the buyer to choose their product over that of a competitor.

There are an abundance of gray areas and variations for methods of site development and staffing. However, as any course is finite, there needs to be some decision made as to the outer edge of a curriculum development plan. The server is a physical border, the servicing of which is a possible area outside content domain. Web scripting languages are vital for a strong foundation in the medium; beyond html and css a designer should have knowledge of some JavaScript and ASP/PHP, but programming is left to programmers. Strategically speaking, an important part of a design course could be site promotion, but marketing a product or service is the domain of marketing specialists. All examples supplied are to some degree artificial and arbitrary, but serve to illustrate the kinds of decisions that need to be made in order to construct a functional course.

\section{Curriculum}

The curriculum of the current option course deals with html and cascading style sheets to a lesser extent, but only as an introduction to other scripting languages. The emphasis is on site construction and design, while the theoretical component focuses on African on-line issues, new media journalism, e-commerce and cyberbroadcasting. With the development of the specialization course in 2001, the aim is to focus this course by changing the dynamics and priorities to accommodate either print or broadcast students. Appendix 3 provides a breakdown of the content skills needed to produce a mainline site today; these being all areas in which students need have some degree of exposure.

The new media specialization course will need to include production and management skills, which current students acquire in their other specialization courses. Students may currently elect to complete a separate course in Computer Aided Research and Reporting, and these skills and tools will need to be integrated with the production skills to produce a true on-line media specialist. Most would have had little graphic training, which would make up a substantial part of the component.

The important aspects of this course are as follows: the need to multi-skill (orientated towards infrastructure), a functional understanding of databases and related scripting language, JavaScript basics and some exposure to other appropriate languages as well as an understanding of the whole production process as it relates to media and commerce. Furthermore, a strong theme through all courses offered by the Rhodes journalism department is the needs and issues of our unique African context. 


\section{National qualifications framework}

The South African Qualifications Authority's national qualifications framework does not have a standards generating body for most Internet-related areas, including Web design or content production. Several contributing factors may be the relative infancy of the Internet as a mainstream entity, its niche birthplace and its many tentacles that refuse to settle, preferring to continuously explore new areas. Seemingly the most complex role to locate within the National Standards Board net is that of content provider, due to its multi-faceted nature and central position.

I have chosen to place my course under the communications subset of Journalism, more specifically aligned with the critical outcome related to the use of technology, in other words using new media tools to tell a story. This appears a simple enough description, but it needs to be a story that is appropriate to the audience and medium. Naturally there is little value in training for the past, so we need to orientate students to the trends of this dynamic medium and equip them with the skills they need to excel. Considering these factors, prospective Web workers need at least an introduction to writing, graphics, photography, audio and video.

Students emerging from this course may be masters of note, yet it is precisely this multifaceted approach that is lacking in most workplaces at present. How many editors with years of experience know how to get their videos on-line and how to repurpose them appropriately? How many reporters know how to structure a story for hyperlinks and understand the Net audience? Until more companies, skills and tasks become increasingly specialized, the Web worker is going to need to produce, or at least manage, all manner of material. However, a much sought-after new skill is developing the ability to handle the full range of material at a basic level, and understanding the dynamics of each media and their relationship to each other - as well as to the final output.

However, on deeper reflection of the OBE Critical Outcomes in Appendix 4, resorting to 'the use of technology towards Journalistic ends' is both simplistic and wholly inadequate. All the outcomes need to be covered, as this is an area of study in and of itself. Further, owing to the immense variety of factors heaped under 'convergence', any course attempting to do justice to skills required and pertinent issues related to new media, will go beyond the confines of journalism. The merging of media leads to multi-skilling, making courses more technical when design studies is already on the border of the term in its conventional sense. The converging of delivery platforms leads to repurposing, and although this may well fall within the curriculum parameters of future journalism courses, it is not yet a clear and formal area of study or research. The marrying of content and delivery, along with content and transactions, takes us into the technical and commercial area, which may be of little interest to anyone, excepting new media content producers.

Both the broadcast and print subset are working on outcomes for new media which may be well placed when considering a specific course or when contemplating their incorporation as part of training programmes for these areas. However, neither necessarily cover what is required by a student training specifically for a career in on-line production. There are many skills in common and both areas should be considering their own needs, but there are strong arguments that the Internet has many unique and uncatered-for demands.

At this stage the core question as to whether the three existing SGBs cover new media sufficiently, or cover their area appropriately, remains unanswered. The underlying concern queries whether they are innovative in this new area or merely reactive with a situation, where the needs of pure on-line 'publications' are insufficiently met. The starting point for such a discussion would be whether new media is sufficiently unique to warrant an SGB? In 
real terms, however, considering the bureaucracy and dynamics involved, could new media issues be successfully incorporated into existing structures with greater representation?

The first wave of on-line media was, very loosely put, the print sector's attempt to manipulate the new medium. The overwhelming lesson experience has afforded us is that the Internet and its audience have little time for 'shovelware' digital newspapers and magazines. It has been suggested that the second wave on our doorsteps is that of broadcasters going on-line; due to bandwidth restrictions they are less likely to take the transition as lightly.

Nevertheless, the fundamental question remains: is our educational system determined to be one step behind the industry trends and needs or one step ahead?

Can we afford to train our students within the narrow confines of the formal structures put into place to guide and advise curriculum development? Students trained according to the recommendations by either the broadcast or print SGBs would be limited by a reactive stance, based on attempts to deal with the perceived threat by advisors and an industry with insufficient understanding of new media issues and potential.

\section{Appendix 1 Possible Web orientation within university departments}

\begin{tabular}{||l||l||}
\hline Site strategist & Management, marketing, media studies, content creators, economics \\
\hline \hline Project management & Management, marketing, content creators \\
\hline \hline Content creators & $\begin{array}{l}\text { Marketing, languages, fine art, journalism, field experts, e.g. } \\
\text { zoology, music }\end{array}$ \\
\hline \hline $\begin{array}{l}\text { On-line content } \\
\text { creators }\end{array}$ & Journalism \\
\hline $\begin{array}{l}\text { Designers } \\
\text { (presentation) }\end{array}$ & Journalism, fine art \\
\hline Database construction & Journalism, computer science, information systems \\
\hline \hline Coding & Journalism (computer science, information systems) \\
\hline \hline Site maintenance & Journalism, computer science, information systems \\
\hline \hline Site promotion & $\begin{array}{l}\text { Marketing, languages, fine art, journalism, field experts, e.g. } \\
\text { zoology, music }\end{array}$ \\
\hline \hline Programming & Computer science, information systems \\
\hline Infrastructure & Computer science, information systems \\
\hline \hline Marketing & Marketing, economics \\
\hline \hline Revenue creation & Management, economics \\
\hline \hline $\begin{array}{l}\text { Business } \\
\text { administration }\end{array}$ & \begin{tabular}{l} 
Accounting, management, economics \\
\hline \hline
\end{tabular} \\
\hline
\end{tabular}

\section{Appendix 2 Site production roles related to content}

\begin{tabular}{|l||l||}
\hline Strategic planning: & Audience needs analysis, revenue models, and competitor analysis \\
\hline $\begin{array}{l}\text { Project } \\
\text { management: }\end{array}$ & Staff and technology requirements, budgets and timelines \\
\hline \hline &
\end{tabular}




\begin{tabular}{|l||l||} 
Site evaluation: & Site functionality, audience perception and competitor analysis \\
\hline \hline $\begin{array}{l}\text { Maintenance } \\
\text { strategy: }\end{array}$ & Continuing site, audience, competitor and market analysis \\
\hline
\end{tabular}

\section{Appendix 3 Skills breakdown}

\begin{tabular}{|c|c|c|}
\hline Message & Structure & Contextual \\
\hline $\begin{array}{l}\text { Content of the } \\
\text { site }\end{array}$ & $\begin{array}{l}\text { Navigation, organization, } \\
\text { look and feel }\end{array}$ & $\begin{array}{l}\text { What is the site about and what does it } \\
\text { mean to me? }\end{array}$ \\
\hline $\begin{array}{l}\text { Content } \\
\text { strategy }\end{array}$ & Coding & Enticing and engaging the audience \\
\hline $\begin{array}{l}\text { Material } \\
\text { selection }\end{array}$ & Programming (client side) & Revenue models \\
\hline $\begin{array}{l}\text { Material } \\
\text { adaptation }\end{array}$ & Browser support & Site scalability \\
\hline $\begin{array}{l}\text { Coding and } \\
\text { encoding }\end{array}$ & $\begin{array}{l}\text { Format and script } \\
\text { specifications }\end{array}$ & Surfer interaction \\
\hline Copy-writing & Archiving & $\begin{array}{l}\text { Banding and integration into company } \\
\text { identity }\end{array}$ \\
\hline Sub-editing & Database creation & Delivery on services \\
\hline $\begin{array}{l}\text { Image } \\
\text { digitizing }\end{array}$ & Server interface & \multirow{2}{*}{$\begin{array}{l}\text { Considering future audience, market, } \\
\text { design and technology trends }\end{array}$} \\
\hline $\begin{array}{l}\text { Graphic } \\
\text { creation }\end{array}$ & Database interface & \\
\hline Animation & & \\
\hline Audio & & \\
\hline Video & & \\
\hline
\end{tabular}

\section{Appendix 4 Outcomes and capabilities}

Critical outcomes to be embedded in all curricula at all levels of the NQF:

- Identify and solve problems

- Work in a team

- Organize and manage own work

- Collect, analyse and evaluate information

- Communicate effectively

- Utilize science and technology

- Recognize problem-solving contexts

\section{Disclaimer}

Articles published in SAJIM are the opinions of the authors and do not necessarily reflect the opinion of the Editor, Board, Publisher, Webmaster or the Rand Afrikaans University. The user hereby waives any claim 
he/she/they may have or acquire against the publisher, its suppliers, licensees and sub licensees and indemnifies all said persons from any claims, lawsuits, proceedings, costs, special, incidental, consequential or indirect damages, including damages for loss of profits, loss of business or downtime arising out of or relating to the user's use of the Website.

ISSN 1560-683X

Published by InterWord Communications for the Centre for Research in Web-based Applications, Rand Afrikaans University 